\title{
Longer storage duration of red blood cells is associated with an increased risk of acute lung injury in patients with sepsis
}

\author{
David R Janz ${ }^{*}$, Zhiguo Zhao ${ }^{2}$, Tatsuki Koyama ${ }^{2}$, Addison K May ${ }^{3}$, Gordon R Bernard', Julie A Bastarache1, \\ Pampee P Young ${ }^{4}$ and Lorraine B Ware ${ }^{1,4}$
}

\begin{abstract}
Background: The storage duration of red blood cells transfused to critically ill patients is associated with increased morbidity and mortality. Whether the association exists between storage duration of red blood cells transfused to patients with sepsis and the risk of developing ALI/ARDS is unknown. We aimed to determine the association of the storage duration of red blood cells transfused to patients with sepsis and risk of developing acute lung injury in the subsequent 96 hours, with comparator trauma and nonsepsis/nontrauma groups.

Methods: We conducted a retrospective observational study of 96 transfused, critically ill patients with sepsis, 176 transfused, critically ill patients with traumatic injury, and 125 transfused, critically ill nontrauma, nonsepsis patients. The primary outcome was the development of ALI/ARDS up to 96 hours after transfusion.

Results: In 96 patients with sepsis, 49 (51\%) patients developed ALI/ARDS. The median storage duration of transfused blood in the ALI/ARDS group was greater (24.5 days, interquartile range (IQR) 20-31) compared with the patients who did not develop ALI/ARDS (21 days, IQR 15-27, $p=0.018$ ). Longer median storage duration was independently associated with an increased risk of developing ALI/ARDS in the subsequent 4 days (odds ratio 1.8, $p=0.028$ ). The same association was not seen in the trauma or nonsepsis, nontrauma patients.

Conclusions: Transfusion of blood with longer median storage duration to patients with sepsis is associated with a higher risk of developing ALI up to 4 days after transfusion. This same association is not seen in other critically ill patient populations.
\end{abstract}

Keywords: Acute respiratory distress syndrome; Transfusion-related acute lung injury; Red blood cell storage lesion

\section{Background}

Anemia is a common problem in critically ill patients and is ubiquitous in those remaining in an ICU for more than 2 days. The treatment of anemia in the ICU includes transfusion of red blood cells (RBCs) and may be used in as many as $40 \%$ of patients [1-3]. The practice of $\mathrm{RBC}$ transfusion to critically ill patients has recently come under scrutiny. Data have emerged describing the potential negative impact that $\mathrm{RBC}$ transfusion may have on outcomes, including increased ICU length of stay [4],

\footnotetext{
* Correspondence: david.janz@vanderbilt.edu

'Department of Medicine, Division of Allergy, Pulmonary, and Critical Care Medicine, Vanderbilt University School of Medicine, 1161 21st Avenue South, T-1218 Medical Center North, Nashville, TN 37232, USA

Full list of author information is available at the end of the article
}

nosocomial infections [5], multiorgan failure [6], acute lung injury [7-11], and mortality [2,12,13]. The pathophysiology underlying these adverse outcomes is not clear, but a growing body of data suggests a relationship with the storage duration of RBCs. With longer storage duration, there is an accumulation in the stored unit of biologically active lipids able to prime neutrophils $[14,15]$, proinflammatory cytokines, such as IL-1, IL-8, TNF- $\alpha$ [16], procoagulant microparticles [17], and oxidants, including free hemoglobin and isoprostanes [18]. Consequently, longer storage duration of RBCs has been associated with some of the same adverse outcomes in humans, including multiorgan failure and increased risk of mortality [19-25], along with acute lung injury in animals [26-29]. However, the potential effect of storage duration 
of RBCs on the development of ALI in at-risk humans has not been systematically investigated nor is it known whether the risk of ALI related to storage duration of $\mathrm{RBCs}$ is consistent across different critically ill patient populations.

Based on the theoretical "two-hit hypothesis" for the development of transfusion-related ALI wherein neutrophils are initially primed by a risk factor (i.e., sepsis) and then activated by components of transfused blood $[14,30]$, patients with sepsis who are exposed to RBCs may be a population at increased risk for ALI after transfusion with blood of a long storage duration. We performed a retrospective observational study to test the hypothesis that the storage duration of transfused blood is associated with an increased risk of developing ALI up to 96 hours after exposure in patients with sepsis. For comparison, we conducted similar analyses in patients with severe trauma and critically ill patients without trauma or sepsis.

\section{Methods}

\section{Study design and patient population}

The study population consisted of 1,334 patients who were enrolled prospectively in the Validating Acute Lung Injury Markers for Diagnosis (VALID) study [31-34] between January 1, 2008 and December 31, 2010. Although patients were enrolled in the VALID study beginning in 2006, electronically accessible blood bank records were not available prior to January 1, 2008. The VALID study aims to identify and validate plasma biomarkers for the diagnosis of ALI and includes patients who are $\geq 18$ years old admitted to the Vanderbilt University Medical Center medical, surgical, cardiovascular, or trauma ICUs and who remain there for at least 2 days. All patients were enrolled on the morning of ICU day 2. A detailed description of study procedures has been published elsewhere [31,32]. All patients were phenotyped daily for ALI/ARDS by two study physicians using the AECC definitions [35] and daily review of radiographs, arterial blood gases, and the medical record.

For the 1,334 patients enrolled in VALID during the study window and after approval by the Vanderbilt University Institutional Review Board (IRB\# 110506), we retrospectively searched their blood bank records to determine whether patients had received a RBC transfusion during the 48 hours before VALID study enrollment. For the 433 patients who had RBC transfusions during this interval, we recorded specific data regarding each unit of RBCs transfused including the date of transfusion and the date of collection from the donor. Storage duration of blood was calculated as the time from donation to transfusion. For inclusion in the sepsis group, patients had to have a diagnosis of sepsis [36] on enrollment into VALID and also have had received transfusion with RBCs in the 48 hours before enrollment. Inclusion in the trauma group required severe traumatic injury leading to ICU admission and receipt of a blood transfusion with RBCs in the 48 hours before enrollment (Figure 1). Patients who were admitted to the ICU with severe traumatic injury who also met criteria for severe sepsis at enrollment $(n=16)$ were excluded from the analysis. All other critically ill patients who received RBCs in the 48 hours before enrollment were classified as nonsepsis, nontrauma. The window for classifying patients with the presence or absence of ALI/ ARDS was 96 hours after enrollment/transfusion. Because some patients developed ALI/ARDS 1 day or more after enrollment and the fixed RBC exposure period of 48 hours before enrollment may not account for all blood exposure for this group, we conducted an additional sensitivity analysis by excluding patients who developed ALI/ARDS 1 day or more after enrollment.

\section{Description of the storage of blood}

All RBCs that were transfused were stored in the Vanderbilt University Medical Center's (VUMC) Blood Bank according to guidelines established by the Food and Drug Administration. Specifically, these units of blood were leukoreduced using the Pall $^{\bullet}$ Cell Processing Set (Ann Arbor, MI) within 24 hours of collection and before storage. The collection center tests $1 \%$ of all filter types collected and manufactured. The quality control is monitored each month and meets the American Academy of Blood Banks requirement of $95 \%$ of products tested pass the leukoreduction requirement. RBCs were not washed nor were any antioxidant solutions added. The maximum storage duration of RBCs at VUMC is 42 days.

\section{Statistical analysis}

We selected, a priori, patients with sepsis, as defined by the consensus definition [36], on enrollment as our population of interest. As the majority (88.5\%) of ALI/ARDS in this group occurred on the day of enrollment into VALID and because the requirement for transfusion-related acute lung injury to develop within 6 hours of transfusion [30] may be too restrictive [37,38], we set an exposure period of 48 hours before VALID enrollment for the analysis. The primary outcome was development of ALI/ARDS during the 96 hours after this exposure period. The same exposure period and outcome windows were applied to the trauma and nontrauma nonsepsis patients.

Transfusion data were summarized using the median storage duration of all RBCs transfused in the 48 hours before enrollment into VALID. We also analyzed the maximum storage duration, defined as the storage duration of the unit of RBCs with the longest storage duration transfused to a patient during the exposure window.

Wilcoxon rank-sum tests were used to compare storage durations between patients with and without acute 


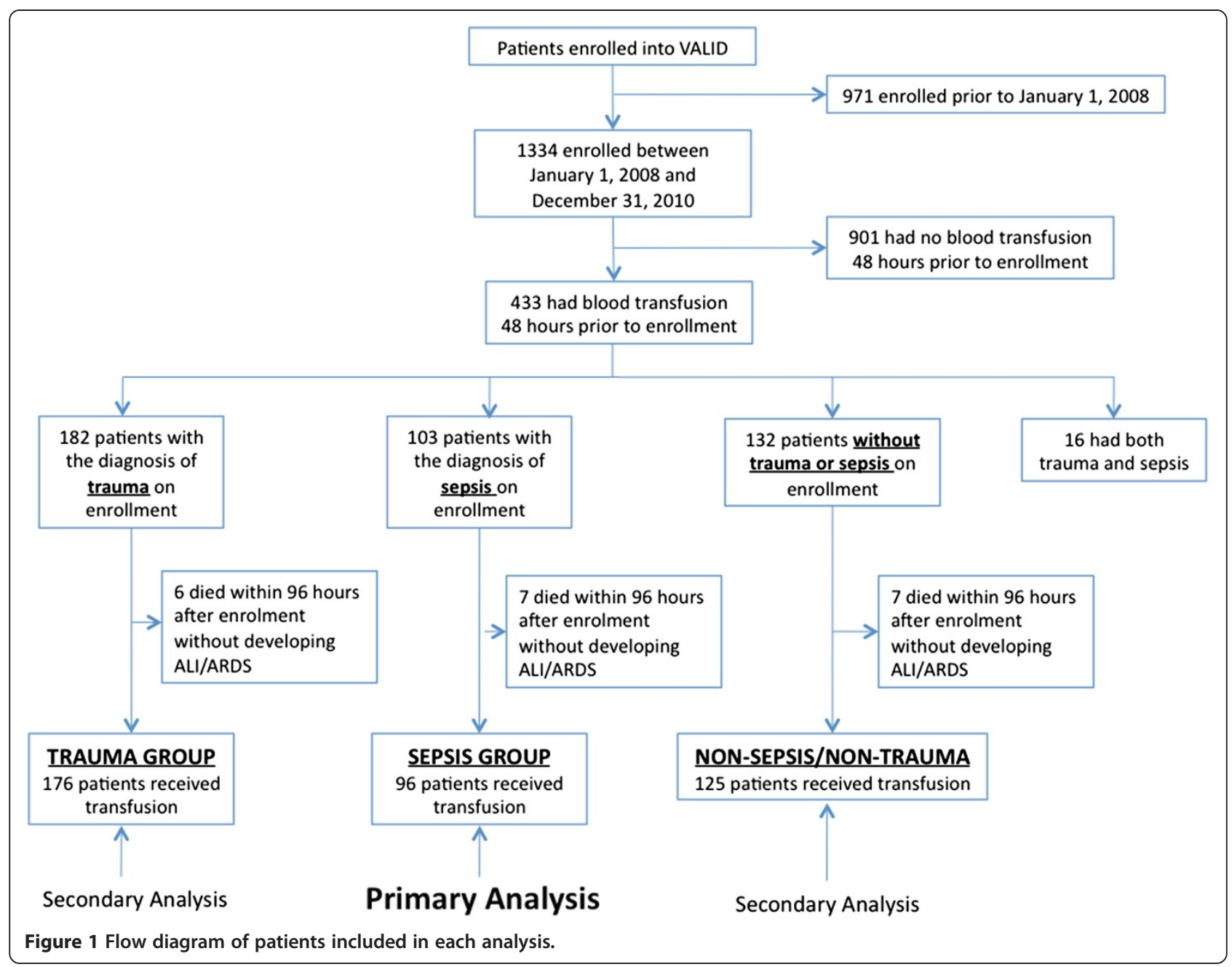

lung injury and Pearson $\chi^{2}$ tests were used to compare categorical variables. Logistic regression models were developed to investigate the associations between the potential risk factors and the primary outcome of ALI/ARDS. Multiple imputation methods were used in the regression models to account for missing data [39]. Penalized maximum likelihood estimation (PMLE) was used to account for the potential impact of model overfitting [40]. A 300iteration bootstrapping was used to validate the PMLE models. All analyses were performed using R 2.12.1 (R Development Core Team, Vienna, Austria). All tests were two-tailed, and a $P$ value of 0.05 or less was considered significant.

\section{Results}

\section{Sepsis patients}

Of the 433 patients enrolled in the VALID study who had RBC transfusions during the 48 hours before enrollment into the VALID study, 96 met diagnostic criteria for sepsis on enrollment and comprised the study population for the primary analysis (Table 1 ). The median storage duration of RBCs transfused to these 96 patients was 23 days, interquartile range (IQR) 18-28 (Figure 2).

In these transfused patients with sepsis, 49 (51\%) developed ALI/ARDS in the 96 hours after transfusion. The median storage duration of RBCs transfused in the patients who developed ALI/ARDS was significantly longer (25 days, IQR 20-31) than the storage duration in those who did not develop ALI/ARDS (21 days, IQR $15-27, p=0.018)$. Similarly, the maximum storage duration of RBCs transfused to the patients who developed ALI/ARDS was significantly longer (26 days, IQR 2233) than the maximum storage duration of RBCs transfused to patients who did not develop ALI/ARDS (24 days, IQR $17-28, p=0.01$ ). The total number of units transfused during the exposure window did not differ between patients who developed ALI/ARDS ( 2 units, IQR 2-3) and those who did not (2 units, IQR 2-4, $p=0.303)$.

After controlling for known risk factors for the development of ALI/ARDS, such as age, APACHE II score on enrollment, smoking status, and number of units 
Table 1 Baseline characteristics of patients with sepsis

\begin{tabular}{llll}
\hline Characteristic & ALI/ARDS $(\mathbf{n}=\mathbf{4 9 )}$ & No ALI/ARDS $(\mathbf{n}=\mathbf{4 7})$ & $\boldsymbol{p}$ value \\
\hline Age & $53(45,62)$ & $61(52,66.5)$ & $0.021^{\mathrm{a}}$ \\
\hline Female gender & $46.9 \%(23)$ & $42.6 \%(20)$ & $0.666^{\mathrm{b}}$ \\
\hline Current smoker & $27.1 \%(13)$ & $31.9 \%(15)$ & $0.606^{\mathrm{b}}$ \\
\hline ICU days & $8(5,14)$ & $6(4,11)$ & $0.118^{\mathrm{a}}$ \\
\hline Ventilator-free days & $18(1,24)$ & $25(7.5,28.0)$ & $0.022^{\mathrm{a}}$ \\
\hline Hospital days & $17(11,26)$ & $14(9.5,26.5)$ & $0.325^{\mathrm{a}}$ \\
\hline Baseline APACHE II score & $29(24,32)$ & $29(22.5,35)$ & $0.751^{\mathrm{a}}$ \\
\hline Blood median storage days & $24.5(20,31)$ & $21(15,26.8)$ & $0.018^{\mathrm{a}}$ \\
\hline Blood maximum storage days & $26(22,33)$ & $24(17,28)$ & $0.01^{\mathrm{a}}$ \\
\hline Number of Units Transfused & $2(2,3)$ & $2(2,4)$ & $0.303^{\mathrm{a}}$ \\
\hline
\end{tabular}

Data given as median ( $25^{\text {th }}$ percentile, $75^{\text {th }}$ percentile) or percent (frequency) of patients.

${ }^{\mathrm{a}}$ Wilcoxon test; ${ }^{\mathrm{b}}$ Pearson test.

transfused, there was a significant increase in the risk of developing ALI/ARDS with exposure to blood of a longer median storage duration (odds ratio (OR) 1.8 for the $75^{\text {th }}$ vs. $25^{\text {th }}$ percentile of storage duration, 95\% CI 1.07-3.04, $p=0.028$; Table 2; Figure 3) and longer maximum storage duration (OR 2.0 for the $75^{\text {th }}$ vs. $25^{\text {th }}$ percentile of storage duration, 95\% CI 1.12-3.58, $p=0.02$; Table 3). The sensitivity analysis excluding 6 patients who developed ALI/
ARDS 1 day or more after enrollment showed similar results, with the odds ratios for median and maximum storage duration remaining significant (OR 2.09, $p=0.018$ and OR 2.29, $p=0.018$, respectively).

\section{Trauma patients}

Of the 433 patients who received RBC transfusions 48 hours before enrollment in the VALID study, 176 patients

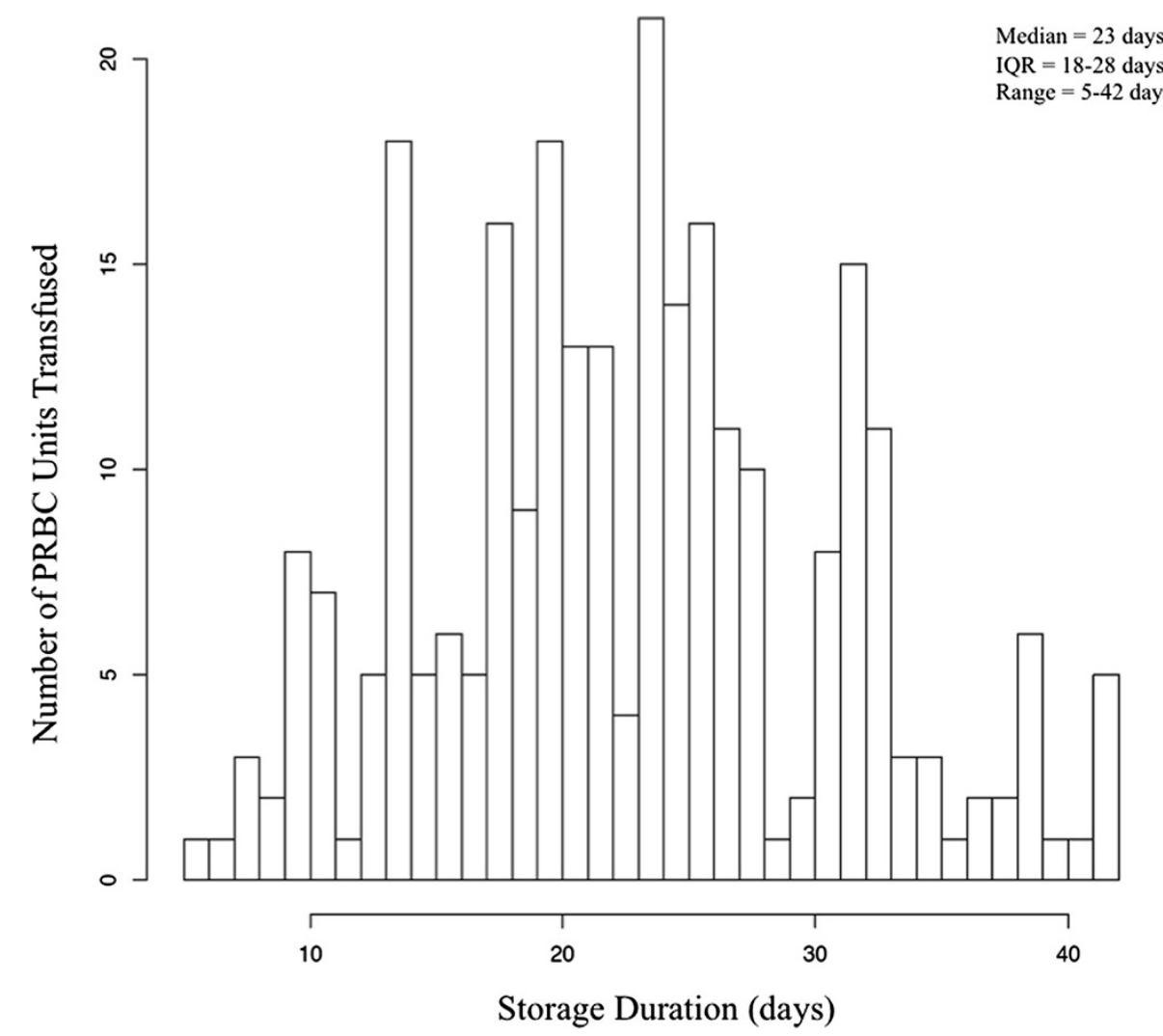

Figure 2 Distribution of storage duration of packed red blood cells transfused to patients with sepsis. 
Table 2 Median storage days and risk of ALI/ARDS in patients with sepsis

\begin{tabular}{llll}
\hline Characteristics & Odds ratio & $\mathbf{9 5 \%} \mathbf{C l}$ & $\boldsymbol{p}$ value \\
\hline Median storage days (28 vs. 18) & 1.8 & $1.07-3.04$ & 0.028 \\
\hline Unit of transfused blood (4 vs. 2) & 0.93 & $0.57-1.52$ & 0.765 \\
\hline Age (65 vs. 47 yr) & 0.62 & $0.37-1.04$ & 0.069 \\
\hline Baseline APACHE II score (33 vs. 23) & 0.87 & $0.51-1.5$ & 0.612 \\
\hline Current smoker (yes vs. no) & 0.93 & $0.42-2.07$ & 0.863
\end{tabular}

Odds ratio for median storage days is the odds of developing ALI/ARDS in the 96 hours after transfusion for the patients receiving RBCs in the $75^{\text {th }}$ compared with $25^{\text {th }}$ percentile of storage duration.

were admitted to an ICU as a result of a traumatic injury, which defined the study population for this secondary analysis (Table 4).

In the trauma study population, $80(45 \%)$ patients were diagnosed with ALI/ARDS in the 4 days following transfusion. The median storage duration of RBCs transfused in the patients who developed ALI/ARDS was not significantly longer (20 days, IQR 14-26) than the storage duration in patients who did not develop ALI/ARDS (20 days, IQR 14-27, $p=0.65$ ). After controlling for age, APACHE II score on enrollment, ISS score on enrollment, smoking status, and number of units transfused, there was no increased risk of developing ALI/ARDS with exposure to blood of a longer median storage duration (OR 0.84 for the $75^{\text {th }}$ vs. $25^{\text {th }}$ percentile of storage duration, CI 0.52-1.35, $p=0.46$ ) nor with blood of a longer maximum storage duration (OR 1.05 for the $75^{\text {th }}$ vs. $25^{\text {th }}$ percentile of storage duration, CI 0.72-1.83, $p=0.57)$.

\section{Nonsepsis, nontrauma patients}

Of the 433 patients enrolled who had RBC transfusions during the VALID study, 125 patients were admitted to an ICU for reasons other than sepsis or trauma, which defined the study population for this secondary analysis (Table 5).

In the nonsepsis, nontrauma study population, 13 (10.4\%) patients were diagnosed with ALI/ARDS in the 4 days following transfusion. The median storage duration of RBCs transfused in the patients who developed ALI/ARDS was not significantly longer (20 days, IQR 17-29) than the storage duration in patients who did not develop ALI/ARDS (22 days, IQR 16-29, $p=1.0$ ). After controlling for age, APACHE II score on enrollment, smoking status, and number of units transfused, there was no increased risk of developing ALI/ARDS with exposure to blood of a longer median storage

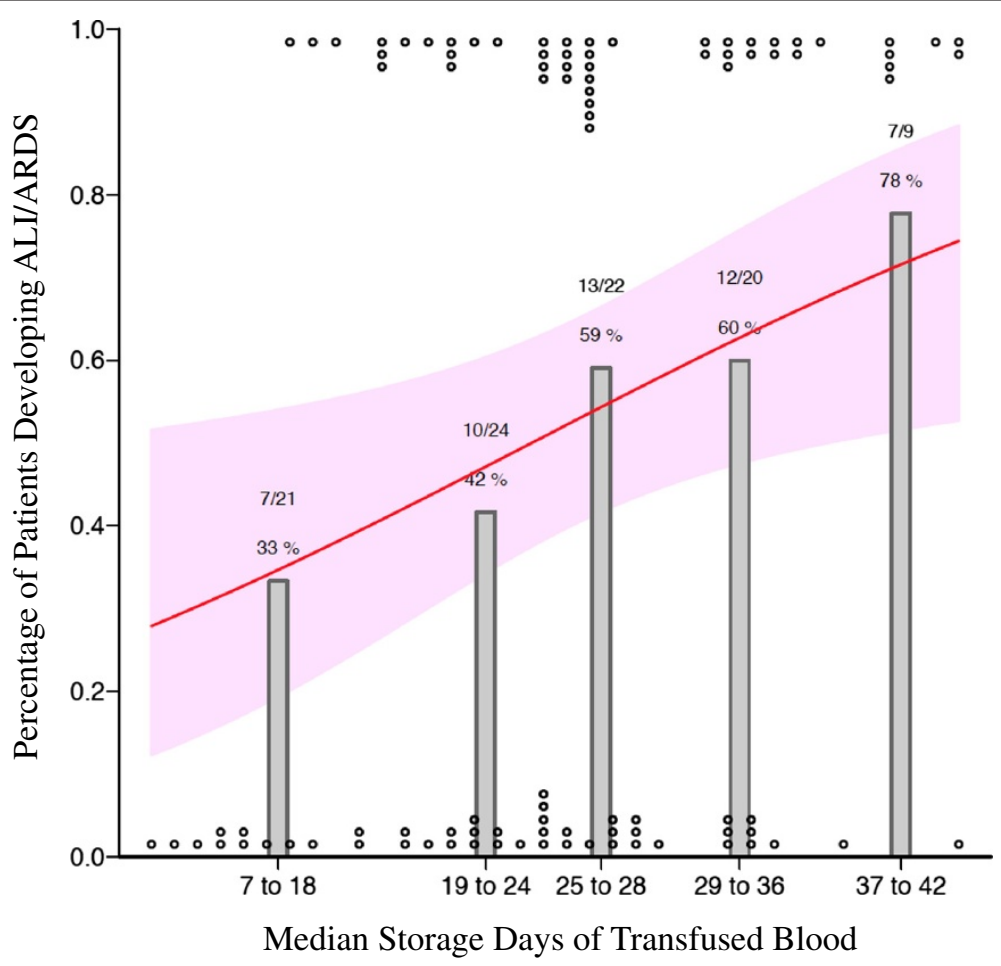

Figure 3 Percentage of sepsis patients developing ALI/ARDS in the 4 days after transfusion and median storage duration of transfused red blood cells. Grey bars represent the percentage of patients with sepsis $(n=96)$ who developed ALI/ARDS during the 96 hours after transfusion. Circles at the top and bottom represent cases and controls placed at their respective median age of transfused blood. The black line and grey confidence band represent a fitted line showing the probability of developing ALI/ARDS derived from the multivariable logistic regression and the corresponding $95 \%$ confidence interval. 
Table 3 Maximum storage days and risk of ALI/ARDS in patients with sepsis

\begin{tabular}{llll}
\hline Characteristics & Odds ratio & $\mathbf{9 5 \% ~ C l}$ & $\boldsymbol{p}$ value \\
\hline Maximum storage days (32 vs. 20) & 2 & $1.12-3.58$ & 0.02 \\
\hline Unit of transfused blood (4 vs. 2) & 0.88 & $0.54-1.45$ & 0.626 \\
\hline Age (65 vs. 47 yr) & 0.64 & $0.38-1.07$ & 0.089 \\
\hline Baseline APACHE II score (33 vs. 23) & 0.89 & $0.52-1.54$ & 0.676 \\
\hline Current smoker (yes vs. no) & 0.86 & $0.39-1.91$ & 0.717
\end{tabular}

Odds ratio for maximum storage days is the odds of developing ALI/ARDS in the 96 hours after transfusion for the patients receiving RBCs in the $75^{\text {th }}$ compared with $25^{\text {th }}$ percentile of maximum storage duration, defined as the unit of RBCs of the longest storage duration received by a patient.

duration (OR 0.94 for the $75^{\text {th }}$ vs. $25^{\text {th }}$ percentile of storage duration, CI $0.36-2.42, p=0.9$ ) nor with blood of a longer maximum storage duration (OR 1.07 for the $75^{\text {th }}$ vs. $25^{\text {th }}$ percentile of storage duration, CI $0.45-2.51$, $p=0.88)$.

\section{Discussion}

In this retrospective, observational study, there was a significant association between the storage duration of RBCs transfused to patients early in the course of sepsis and the risk of developing ALI/ARDS up to 4 days after exposure that was independent of the amount of blood transfused. This association was not seen across other critically ill patient populations, including patients with severe traumatic injuries.

Although several reports have described an increased risk of ALI/ARDS with transfusion of RBCs to critically ill patients that is amplified by the number of units of RBCs transfused [7-11], the current study is unique in that it describes an increased risk of ALI/ARDS in humans with increasing storage duration of blood that is independent of the number of units transfused. In rats and sheep exposed

Table 4 Baseline characteristics of the trauma cohort

\begin{tabular}{llll}
\hline Characteristic & $\begin{array}{l}\text { ALI/ARDS } \\
(\mathbf{n}=\mathbf{8 0})\end{array}$ & $\begin{array}{l}\text { No ALI/ARDS } \\
(\mathbf{n}=\mathbf{9 6})\end{array}$ & $\boldsymbol{p}$ value \\
\hline Age $(\mathrm{yr})$ & $51(36,63)$ & $46(29,59)$ & $0.094^{\mathrm{a}}$ \\
\hline Female gender & $28.8 \%(23)$ & $24.0 \%(23)$ & $0.471^{\mathrm{b}}$ \\
\hline Current smoker & $46.3 \%(31)$ & $46.5 \%(40)$ & $0.976^{\mathrm{b}}$ \\
\hline ICU days & $12(7,16)$ & $8(5,13)$ & $0.014^{\mathrm{a}}$ \\
\hline Ventilator-free days & $17(12,22)$ & $21(16,24)$ & $<0.001^{\mathrm{a}}$ \\
\hline Hospital days & $16(11,24)$ & $15(10,23)$ & $0.281^{\mathrm{a}}$ \\
\hline Baseline APACHE II score & $27(24,31)$ & $26(22,30)$ & $0.035^{\mathrm{a}}$ \\
\hline Baseline ISS score & $34(29,41)$ & $28(19,37)$ & $0.011^{\mathrm{a}}$ \\
\hline Blood median storage days & $20(14,26)$ & $20(14,27)$ & $0.651^{\mathrm{a}}$ \\
\hline Blood maximum storage days & $25(19,32)$ & $25(19,31)$ & $0.583^{\mathrm{a}}$ \\
\hline Number of units transfused & $4(2,6)$ & $4(2,9)$ & $0.465^{\mathrm{a}}$ \\
\hline
\end{tabular}

Data given as median ( $25^{\text {th }}$ percentile, $75^{\text {th }}$ percentile) or percent (frequency) of patients.

${ }^{\mathrm{a}}$ Wilcoxon test; ${ }^{\mathrm{b}}$ Pearson test.
Table 5 Baseline characteristics of the nonsepsis, nontrauma cohort

\begin{tabular}{llll}
\hline Characteristic & $\begin{array}{l}\text { ALI/ARDS } \\
(\mathbf{n}=\mathbf{1 3})\end{array}$ & $\begin{array}{l}\text { No ALI/ARDS } \\
(\mathbf{n}=\mathbf{1 1 2})\end{array}$ & $\boldsymbol{p}$ value \\
\hline Age $(\mathrm{yr})$ & $56(48,59)$ & $61(49.8,68)$ & $0.191^{\mathrm{a}}$ \\
\hline Female gender & $69.2 \%(9)$ & $43.8 \%(49)$ & $0.081^{\mathrm{b}}$ \\
\hline Current smoker & $30.8 \%(4)$ & $24.3 \%(27)$ & $0.612^{\mathrm{b}}$ \\
\hline ICU days & $6(3,8)$ & $5(3,9)$ & $0.827^{\mathrm{a}}$ \\
\hline Ventilator-free days & $24(16,26)$ & $26(23,27)$ & $0.094^{\mathrm{a}}$ \\
\hline Hospital days & $16(11,21)$ & $11(7,20.3)$ & $0.337^{\mathrm{a}}$ \\
\hline Baseline APACHE II score & $26(24,29)$ & $26(22,31)$ & $0.711^{\mathrm{a}}$ \\
\hline Blood median storage days & $20(17,29)$ & $22(16,29)$ & $1^{\mathrm{a}}$ \\
\hline Blood maximum storage days & $26(19,35)$ & $26.5(20,33)$ & $0.907^{\mathrm{a}}$ \\
\hline Number of units transfused & $4(2,5)$ & $4(2,8)$ & $0.88^{\mathrm{a}}$ \\
\hline Data
\end{tabular}

Data given as median ( $25^{\text {th }}$ percentile, $75^{\text {th }}$ percentile) or percent (frequency) of patients.

$\mathrm{N}$ is the number of nonmissing values.

${ }^{\mathrm{a}}$ Wilcoxon test; ${ }^{\mathrm{b}}$ Pearson test.

to a "first-hit" (lipopolysaccharide, LPS) as a model of clinical sepsis, transfusion of blood of a longer storage duration caused more severe lung inflammation and ALI compared with fresh blood [27-29,41]. Increased lung inflammation and injury were only observed in those animals that received the dual insult of LPS and blood of a longer storage duration; animals that were transfused with blood of a longer storage duration without LPS exposure had similar rates of ALI compared with controls. Concordant with these animal studies, in the current study, transfusion with blood of a longer storage duration was only associated with ALI in patients with severe sepsis; the association was not seen in severe trauma or critically ill patients who had neither trauma nor sepsis. We did not find an association between the number of units transfused and ALI as others have reported [7-11], which may be explained by our patient population receiving fewer units of blood (median of 2 units RBCs per patient).

Transfusion-related acute lung injury (TRALI) is strictly defined as the onset of ALI/ARDS within 6 hours of a blood transfusion that is not explained by another risk factor [30]. In the current study, we aimed to capture all ALI/ARDS events occurring after transfusion, not just ALI/ARDS that met the strict TRALI definition. We hypothesized that injurious mediators in stored blood might potentiate acute lung injury in the setting of other mediators of acute lung injury, such as sepsis and that this potentiation would not be limited to a 6-hour window after transfusion. For this reason, we had a 48-hour exposure window and included cases of ALI/ ARDS occurring as long as 4 days after the exposure, although the majority (88.5\%) of cases occurred in the 24 hours after enrollment. Our findings suggest that the risk of ALI/ARDS associated with transfusion in patients 
with sepsis may continue beyond the 6-hour window that is used to define TRALI [37]. The numerous changes that occur during the storage of RBCs [38] add biologic plausibility to the observation that the potential for poor outcomes is not limited to 6 hours after transfusion.

The current study has several limitations. The retrospective observational design can only suggest association rather than causation. Second, because the vast majority of sepsis patients who developed ALI/ARDS met the criteria for ALI/ARDS at the time of enrollment into the VALID study on the morning of ICU day 2, we used a fixed exposure period of 48 hours before enrollment for ascertainment of RBC exposure; however, there were six patients in the sepsis group who did not develop ALI/ ARDS until the days subsequent to enrollment and some of these patients received transfusions beyond the exposure period. As these units of RBCs were unaccounted for in our primary analysis and to ensure these patients were not significantly influencing our results, we repeated the analysis without these patients and still found a significant association. We only studied patients in VALID who had received RBCs before enrollment, which limited our sample size to 96 sepsis patients, 176 trauma patients, and 125 nonsepsis nontrauma patients. Additionally, in the nonsepsis nontrauma subset, there were only 13 patients who developed ALI/ARDS, which significantly limits the power to say anything definitive about this group of patients. Nonetheless, the association between storage duration and ALI/ARDS in patients with sepsis was robust across multiple analyses. Finally, the difference in our study in storage duration of RBCs transfused to patients with sepsis was only 4 days and included transfusion of RBCs of varying age to the same patient, whereas previously published work has focused on transfusion of RBCs of a homogenous storage duration and had greater differences in the storage duration between groups [24,42]. The relatively small difference in storage duration in our study may suggest a less biologically meaningful finding; however, this may rather suggest that even small differences in storage duration are meaningful when transfusing critically ill patients.

Our findings are not concordant with the results of a randomized trial comparing transfusion of fresh blood to blood of longer storage duration in critically ill patients, which showed no difference in the development of ALI between groups [42]. The disparity in results could be due in part to that study being underpowered to detect a difference in this secondary outcome, a problem that might be overcome by a larger, randomized trial currently underway [43]. In addition, animal models and our current findings suggest that signals for increased risk of ALI/ARDS after transfusion may be more robust in septic patient populations rather than heterogeneous, critically ill patient populations as studied in this randomized trial that included only $6(6 \%)$ patients with sepsis. Although not focused on the development of ALI/ARDS, past studies of trauma patients $[7,22,25,44,45]$ showed that the storage duration of RBCs was associated with worse clinical outcomes, which is in contrast to our results. This difference may potentially be explained by a markedly higher median number of RBCs received in the past studies (12 units per patient) [22] compared with our current study (median 4 units per patient in the trauma group). Finally, there is existing data in trauma patients and patients having undergone coronary artery bypass grafting that potential signs of ALI/ARDS (respiratory insufficiency, increased time on the ventilator and pneumonia) more often were found in patients receiving blood of a longer storage duration $[24,45]$; however, the presence of ALI/ARDS in these patients was not reported.

Our study has potential implications for future research. There was a significant association not only with the median storage duration of transfused blood but also with the maximum storage duration of all units transfused. These findings suggest that there might be increased risk of morbidity and mortality with exposure to even a single unit of RBCs with long storage duration. The current study adds ALI/ARDS to a list of morbidities associated with increasing storage duration of transfused RBCs. Research focusing on the mechanisms that drive the storage lesion and its end-organ effects will provide us with targets for preventative therapy in patients unable to avoid transfusion. Larger, prospective studies are needed to determine which patients (sepsis, trauma, etc.) who required transfusion are at highest risk from aged blood and what threshold delineates hazardous storage duration. Only with additional prospective clinical studies will we be able to create evidenced-based guidelines for transfusion to limit both transfusion rates and transfusion-related morbidity, such as ALI/ARDS.

\section{Conclusions}

Transfusion of blood with longer median storage duration to patients with early sepsis is associated with a higher risk of developing ALI up to 4 days after transfusion, whereas this same association is not seen in patients with trauma or critically ill patients without sepsis or trauma. This may suggest that the storage duration of RBCs transfused to critically ill patients may have variable effects depending on the underlying cause of a patient's illness.

\section{Abbreviations}

ICU: Intensive Care Unit; RBCs: Packed red blood cells; ALI: Acute lung injury; ARDS: Acute Respiratory Distress Syndrome; VALID: Validating acute lung injury markers for diagnosis; IQR: Interquartile range; APACHE: Acute physiology and chronic health evaluation; OR: Odds ratio. 


\section{Competing interests}

The authors declare that they have no competing interests.

\section{Authors' contributions}

$D R J, J A B, P P Y$, and LBW were involved in the study design. DRJ, BC, AKM, GRB, and PPY collected the data. DRJ, TK, ZZ, and LBW performed the statistical analysis. DRJ drafted the manuscript and all authors participated in the revision of this manuscript. All authors read and approved the final manuscript.

\section{Sources of funding}

Supported in part by the Vanderbilt CTSA grant UL1 RR024975-01 from NCRR/NIH, NIH HL103836, NIH HL090785, an American Heart Association Clinical Research Award, and an American Heart Association Established Investigator Award.

\section{Author details}

${ }^{1}$ Department of Medicine, Division of Allergy, Pulmonary, and Critical Care Medicine, Vanderbilt University School of Medicine, 1161 21st Avenue South, T-1218 Medical Center North, Nashville, TN 37232, USA. ²Department of Biostatistics, Vanderbilt University, Nashville, TN, USA. ${ }^{3}$ Department of Biostatistics, Vanderbilt School of Medicine, Nashville, TN, USA. ${ }^{4}$ Department of Pathology, Microbiology and Immunology, Vanderbilt University School of Medicine, Nashville, TN, USA.

Received: 5 June 2013 Accepted: 10 September 2013

Published: 24 September 2013

\section{References}

1. Corwin HL, Gettinger A, Pearl RG, Fink MP, Levy MM, Abraham E, Maclntyre NR, Shabot MM, Duh MS, Shapiro MJ: The CRIT study: anemia and blood transfusion in the critically ill - current clinical practice in the United States. Crit Care Med 2004, 32:39-52.

2. Vincent JL, Baron JF, Reinhart K, Gattinoni L, Thijs L, Webb A, MeierHellmann A, Nollet G, Peres-Bota D, ABC (Anemia and Blood Transfusion in Critical Care) Investigators: Anemia and blood transfusion in critically ill patients. JAMA 2002, 288:1499-1507.

3. Adam RC, Lundy JS: Anesthesia in cases of poor risk: some suggestions for decreasing the risk. Surg Gynecol Obstet 1942, 74:1011-1101.

4. Fransen E, Maessen J, Dentener M: Impact of blood transfusions on inflammatory mediator release in patients undergoing cardiac surgery. Chest 1999, 116:1233-1239.

5. Taylor RW, O'Brien J, Trottier SJ, Manganaro L, Cytron M, Lesko MF, Arnzen K, Cappadoro C, Fu M, Plisco MS, Sadaka FG, Veremakis C: Red blood cell transfusions and nosocomial infections in critically ill patients. Crit Care Med 2006, 34:2302-2308.

6. Moore FA, Moore EE, Sauaia A: Blood transfusion: an independent risk factor for postinjury multiple organ failure. Arch Surg 1997, 132:620-625.

7. Croce MA, Tolley EA, Claridge JA, Fabian TC: Transfusions result in pulmonary morbidity and death after a moderate degree of injury. J Trauma 2005, 59:19-24.

8. Gong MN, Thompson BT, Williams P, Pothier L, Boyce PD, Christiani DC: Clinical predictors of and mortality in acute respiratory distress syndrome: potential role of red cell transfusion. Crit Care Med 2005, 33:1191-1198

9. Zilberberg MD, Carter C, Lefebvre P, Raut M, Vekeman F, Duh MS, Shorr AF: Red blood cell transfusions and the risk of acute respiratory distress syndrome among the critically ill: a cohort study. Crit Care 2007, 11:R63.

10. Gajic O, Dara SI, Mendez UL, Adesanya AO, Festic E, Caples SM, Rana R, St Sauver JL, Lymp JF, Afessa B, Hubmayr RD: Ventilator-associated lung injury in patients without acute lung injury at the onset of mechanical ventilation. Crit Care Med 2004, 32:1817-1824.

11. Silverboard H, Aisiku I, Martin GS, Adams M, Rozycki G, Moss M: The role of acute blood transfusion in the development of acute respiratory distress syndrome in patients with trauma. J Trauma 2005, 59:717-723.

12. Hebert PC, Wells G, Blajchman MA, Marshall J, Martin C, Pagliarello G, Tweeddale M, Schweitzer I, Wetisir E: A multicenter, randomized, controlled clinical trial of transfusion requirements in critical care. $N$ Engl J Med 1999, 340:409-417.
13. Malone DL, Dunne J, Tracy JK, Putnam AT, Scalea TM, Napolitano LM: Blood transfusion, independent of shock severity is associated with worse outcome in trauma. Trauma 2003, 54:898-907.

14. Silliman CC: The two-event model of transfusion-related acute lung injury. Crit Care Med 2006, 34:S124-S131.

15. Silliman CC, Moore EE, Kelher MR, Kahn SY, Gellar L, Elzi DJ: Identification of lipids that accumulate during the routine storage of prestorage leukoreduced red blood cells and cause acute lung injury. Transfusion 2011, 51:2549-2554.

16. Ho J, Sibbald WJ, Chin-Yee H: Effects of storage on efficacy of red cell transfusion: when is it not safe? Crit Care Med 2003, 31:S687-S697.

17. Jy W, Shariatmadar S, Gomez-Marin O, Horstman LH, Ahn YS: Microparticles in stored red blood cells as potential mediators of transfusion complications. Transfusion 2011, 51:886-893.

18. Grimshaw K, Sahler J, Spinelli SL, Phipps RP, Blumberg N: New frontiers in transfusion biology: identification and significance of mediators of morbidity and mortality in stored red blood cells. Transfusion 2011, 51:874-880

19. Leal-Noval SR, Jara-Lopez I, Garcia-Garmendia JL, Marin-Niebla A, HerruzoAviles A, Camacho-Larana P, Loscertales J: Influence of erythrocyte concentrate storage time on postsurgical morbidity in cardiac surgery patients. Anesthesiology 2003, 98:815-822.

20. Wasser MN, Houbiers JG, D'Amaro J, Hermans J, Huysmans HA, Van Konijnenburg GC, Brand A: The effect of fresh versus stored blood in post-operative bleeding after coronary bypass surgery: a prospective randomized study. Brit J Haem 1989, 72:81-84.

21. Marik PE, Sibbald WJ: Effect of stored-blood transfusion on oxygen delivery in patients with sepsis. JAMA 1993, 269:3024-3029.

22. Zallen G, Offner PJ, Moore EE, Blackwell J, Ciesla DJ, Gabriel J, Denny C, Silliman CC: Age of transfused blood is an independent risk factor for postinjury multiple organ failure. Am J Surg 1999, 178:570-572.

23. Purdy FR, Tweeddale MG, Merrick PM: Association of mortality with age of blood transfused in septic ICU patients. Can J Anaesth 1997, 44:1256-1261.

24. Koch CG, Li L, Sessler DI, Figueroa P, Hoeltge GA, Mihaljevic T, Blackstone $\mathrm{EH}$ : Duration of red-cell storage and complications after cardiac surgery. N Eng J Med 2008, 358:1229-1239.

25. Hassan M, Pham TN, Cuschieri J, Warner KJ, Nester T, Maier RV, Shalhub S, O'Keefe GE: The association between the transfusion of older blood and outcomes after trauma. Shock 2011, 35:3-8

26. Silliman CC, Bjornsen AJ, Wyman TH, Kelher M, Allard J, Bieber S, Voelkel NF: Plasma and lipids from stored platelets cause acute lung injury in an animal model. Transfusion 2003, 43:633-640.

27. Kelher MR, Masuno T, Moore EE, Damle S, Meng X, Song Y, Liang X, Niedzinski J, Geier SS, Khan SY, Gamboni-Robertson F, Silliman CC: Plasma from stored packed red blood cells and MHC class I antibodies causes acute lung injury in a 2-event in vivo rat model. Blood 2009, 113:2079-2087.

28. Tung JP, Fung YL, Nataatmadja M, Colebourne Kl, Esmaeel HM, Wilson K, Barnett AG, Wood P, Silliman CC, Fraser JF: A novel in vivo ovine model of transfusion-related acute lung injury (TRALI). Vox Sang 2011, 100:219-230.

29. Tung JP, Frasser JF, Nataatmadja M, Colebourne KI, Barnett AG, Glenister KM, Zhou AY, Wood P, Silliman CC, Fung YL: Age of blood and recipient factors determine the severity of transfusion-related acute lung injury (TRALI). Crit Care 2012, 16:T19.

30. Toy P, Popovsky MA, Abraham E, Ambruso DR, Holness LG, Kopko PM, McFarland JG, Nathens AB, Silliman CC, Stroncek D, National Heart, Lung and Blood Institute Working Group on TRALI: Transfusion-related acute lung injury: definition and review. Crit Care Med 2005, 33:721-726.

31. Siew ED, Ware LB, Gebretsadik T, Shintani A, Moons KG, Wickersham N, Bossert F, Ikizler TA: Urine neutrophil gelatinase-associated lipocalin moderately predicts acute kidney injury in critically ill adults. J Am Soc Nephrol 2009, 20:1823-1832.

32. Siew ED, Ikizler TA, Gebretsadik T, Shintani A, Wickersham N, Bossert F, Peterson JF, Parikh CR, May AK, Ware LB: Elevated urinary IL-18 levels at the time of ICU admission predict adverse clinical outcomes. Clin J Am Soc Nephrol 2010, 5:1497-1505.

33. O'Neal HR, Koyama T, Koehler EA, Siew E, Curtis BR, Fremont RD, May AK, Bernard GR, Ware LB: Prehospital statin and aspirin use and the prevalence of severe sepsis and acute lung injury/acute respiratory distress syndrome. Crit Care Med 2011, 39:1343-1350. 
34. Janz DR, Bastarache JA, Peterson JF, Sills G, Wickersham N, May AK, Roberts $\sqcup$ 2nd, Ware LB: Association between cell-free hemoglobin, acetaminophen, and mortality in patients with sepsis: an observational study. Crit Care Med 2013, 41:784-790.

35. Bernard GR, Artigas A, Brigham KL, Carlet J, Falke K, Hudson L, Lamy M, Legall JR, Morris A, Spragg R: The American-European Consensus Conference on ARDS. Definitions, mechanisms, relevant outcomes, and clinical trial coordination. Am J Resp Crit Care Med 1994, 149:818-824

36. Bone RC, Balk RA, Cerra FB, Dellinger RP, Fein AM, Knaus WA, Schein RM, Sibbald WJ: Definitions for sepsis and organ failure and guidelines for the use of innovative therapies in sepsis. The ACCP/SCCM consensus conference committee. Chest 1992, 101:1644-1655.

37. Marik PE, Corwin HL: Acute lung injury following blood transfusion: expanding the definition. Crit Care Med 2008, 36:3080-3084.

38. Chin-Yee I, Arya N, d'Almeida MS: The red cell storage lesion and its implication for transfusion. Transfus Sci 1997, 18:447-458.

39. Yang S, Prentice RL: Semiparametric inference in the proportional odds regression model. J Am Stat Assoc 1999, 94:125-136.

40. Moons KG, Donders AR, Steyerberg EW, Harrell FE: Penalized maximum likelihood estimation to directly adjust diagnostic and prognostic prediction models for overoptimism: a clinical example. J Clin Epidemiol 2004, 57:1262-1270.

41. Vlaar AP, Hofstra JJ, Kilik W, Van Lenthe H, Nieuwland R, Schultz MJ, Levi MM, Roelofs JJ, Tool AT, De Korte D, Juffermans NP: Supernatant of stored platelets causes lung inflammation and coagulopathy in a novel in vivo transfusion model. Blood 2010, 116:1360-1386.

42. Kor DJ, Kashyap R, Weiskopf RB, Wilson GA, Van Buskirk CM, Winters JL, Malinchoc M, Hubmayr RD, Gajic O: Fresh red blood cell transfusion and short-term pulmonary, immunologic, and coagulation status: a randomized clinical trial. Am J Resp Crit Care Med 2012, 185:842-850.

43. Lacroix J, Hebert PC, Fergusson D, Tinmouth A, Blajchman MA, Callum J, Cook D, Marshall JC, McIntyre L, Turgeon AF, ABLE study group: The age of blood evaluation (ABLE) randomized controlled trial: study design. Transfus Med Rev 2011, 25:197-205.

44. Kiraly LN, Underwood S, Differding JA, Schreiber MA: Transfusion of aged packed red blood cells results in decreased tissue oxygenation in critically injured trauma patients. J Trauma 2009, 67:29-32.

45. Vandromme MJ, McGwin G, Marques MB, Kerby JD, Rue LW 3rd, Weinberg JA: Transfusion and pneumonia in the trauma intensive care unit: an examination of the temporal relationship. J Trauma 2009, 67:97-101.

doi:10.1186/2110-5820-3-33

Cite this article as: Janz et al.: Longer storage duration of red blood cells is associated with an increased risk of acute lung injury in patients with sepsis. Annals of Intensive Care 2013 3:33.

\section{Submit your manuscript to a SpringerOpen ${ }^{\circ}$ journal and benefit from:}

- Convenient online submission

- Rigorous peer review

- Immediate publication on acceptance

- Open access: articles freely available online

- High visibility within the field

- Retaining the copyright to your article

Submit your next manuscript at $\gg$ springeropen.com 